\title{
Genetic System for Project Support with the Sequencing Problem
}

\section{Autores}

Amelec Viloria, Noel Varela, Carlos Herazo-Beltran, Omar Bonerge Pineda Lezama, Alberto Mercado, Jairo Martinez Ventura, Hugo Hernandez Palma

\begin{abstract}
One of the main problems faced by manufacturing companies in the production sequencing, also called scheduling, which consists of identifying the best way to order the production program on the machines for improving efficiency. This paper presents the integration of a simulation model with an optimization method to solve the problem of dynamic programming with stochastic demand.

Palabras clave

Simulation, Programming, Dynamic sequencing, Job shop, Stochastic demand
\end{abstract}

